\title{
A UTILIZAÇÃO DOS MAPAS AFETIVOS COMO POSSIBILIDADE DE LEITURA DO TERRITÓRIO NO CRAS
}

Diego Menezes Augusto

Universidade Federal do Ceará- UFC

Maria Zelfa de Souza Feitosa

Universidade Federal do Ceará- UFC

\section{Zulmira Áurea Cruz Bomfim}

Universidade Federal do Ceará- UFC

\begin{abstract}
Resumo
Baseados em pesquisas e em nossa experiência profissional, nos sentimos impelidos a buscar caminhos para o trabalho no CRAS, no processo de territorialização. Nossa proposta visa superar a mera divisão do território e identificação de equipamentos e beneficiários dos programas de transferência de renda, a partir da discussão de metodologias que envolvam profissionais e usuários, embasadas no compromisso ético-político com a comunidade. Assim, encontramos na Psicologia Ambiental estratégias pertinentes a esta empreitada. Objetivamos neste artigo apresentar o Instrumento Gerador dos Mapas Afetivos como método capaz de auxiliar o psicólogo do CRAS, no processo de territorialização. No CRAS, os Mapas Afetivos proporcionam um desenho do território em sua integralidade, visibilizando a relação usuárioambiente, a partir dos modos como os sujeitos comunitários implicam-se com seu lugar de moradia.
\end{abstract}

Palavras-chave: práticas de psicologia; territorialização; afeto.

\section{AFFECTIVE MAPS USE AS POSSIBILITY OF TERRITORIAL READING IN SOCIAL ASSISTENCE REFERENCE CENTER - CRAS}

\begin{abstract}
Based on surveys and our professional experience, we feel impelled to seek ways to work in CRAS in the territorialization process. Our proposal aims to overcome the mere division of the territory and identification of facilities and beneficiaries of income transfer governmental programs as from the discussion of methodologies involving professionals and users, supported on ethical and political commitment to the community. Thus, we find in Environmental Psychology relevant strategies to this endeavor. We aim to present the Affective Maps Generator Instrument as a method able to assist the CRAS' Psychologist in the territorialization process. In CRAS, the Affective Maps provide a design of the studied area in its entirety, enables userenvironment relationship visualization, as from the ways in which community subjects imply with their residence places.
\end{abstract}

Keywords: psychology practice; territorialization; affection. 


\title{
EL USO DE MAPAS AFECTIVOS COMO POSIBILIDAD DE LECTURA DEL TERRITORIO EN EL CENTRO DE REFERENCIA DE ASISTENCIA SOCIAL - CRAS
}

\begin{abstract}
Resumen
Basados en investigaciones y en nuestra experiencia profesional, nos sentimos impulsados a buscar maneras para el trabajo en el CRAS, en el proceso de territorialización. Nuestra propuesta busca superar la mera división de territorio y la identificación de los equipamientos y los beneficiarios de los programas de transferencia de renta a partir de la discusión de metodologías que incluyan los profesionales y los usuarios, apoyados en el compromiso ético y político con la comunidad. Así, encontramos en la Psicología Ambiental estrategias pertinentes a este esfuerzo. Objetivamos presentar el Generador Instrumento de Mapas Afectivos como método capaz de ayudar al psicólogo en el proceso de territorialización. En el CRAS, los mapas afectivos proporcionan un diseño del área en su totalidad permitiendo la visualización de la relación usuario-medio ambiente, desde el modo como los sujetos de la comunidad se implican con su lugar de moradia.
\end{abstract}

Palabras clave: práctica del psicólogo; territorialización; afecto.

\section{INTRODUÇÃO}

O CRAS é um equipamento socioassistencial criado no bojo do processo de construção do Sistema Único de Assistência Social (SUAS), a partir da aprovação da Política Nacional de Assistência Social (PNAS) pelo Conselho Nacional de Assistência Social (CNAS). Em 2004, com o surgimento deste Sistema, novas políticas sociais foram elaboradas em consonância com projetos que visavam à prevenção e proteção de famílias em situação de risco e vulnerabilidade social, contra as intempéries da vida em condição de pobreza. Dentre os equipamentos que dão vida ao SUAS, há o Centro de Referência de Assistência Social (CRAS), que no âmbito da Proteção Social Básica (PSB) tem o fito de fortalecer os vínculos afetivos das famílias que, prioritariamente, são beneficiárias do Programa Bolsa Família (PBF) e do Benefício de Prestação Continuada (BPC) como também os laços comunitários das famílias do território de abrangência do CRAS (Brasil, 2009).

Neste equipamento, o psicólogo é convidado a intervir numa perspectiva interdisciplinar, orientando sua prática à prevenção de situações geradoras de vulnerabilidade social, em conjunto com ações que primam pelo fortalecimento de vínculos familiares e comunitários das pessoas que residem em seu território de abrangência. O presente artigo objetiva apresentar o Instrumento Gerador dos Mapas Afetivos (Bomfim, 2010) como um método capaz de auxiliar os psicólogos no processo de territorialização no CRAS.

Ao lado da Matricialidade Sociofamiliar, o processo de territorialização se constitui como eixo estruturante do CRAS (BRASIL, 2009). Neste processo, o território de abrangência do serviço é descrito de maneira a serem identificados seus usuários, familiares, equipamentos, cultura do lugar, entre outros aspectos. O território é identificado como espaço humano vivo, no qual a história dos sujeitos individual e coletivamente se constrói, é atravessado por relações de 
poder, lugar em que os riscos e as vulnerabilidades sociais se estabelecem e onde as potencialidades comunitárias geram modos de enfrentamento às condições de sofrimento. Por conta disso, Brasil (2009) e Carlson e Pinheiro (2013) afirmam que conhecer e viver o território da comunidade é de fundamental importância tanto para a identificação das fragilidades como para o fortalecimento das potencialidades e da rede socioassistencial aí presentes, garantindo a prevenção e o enfrentamento das vulnerabilidades. Portanto, a família, foco da PNAS, e o território são centrais nas ações do Serviço de Proteção e Atenção Integral às Famílias (PAIF), do Serviço de Convivência e Fortalecimento de Vínculos (SCFV) e nos demais serviços socioassistenciais ofertados pelo CRAS.

Conforme o Ministério do Desenvolvimento e Combate à Fome (MDS), atualmente há mais de 7.000 mil CRAS no nosso país. Desde sua origem, este equipamento conta com profissionais de Psicologia que, independente da sua formação, encontram no CRAS a possibilidade de exercer sua profissão. Entretanto, espera-se do psicólogo uma atuação pertinente aos princípios e objetivos do CRAS, o que, impreterivelmente, exclui toda e qualquer ação de cunho psicoterápico, pois "Conforme normatizado pela Tipificação Nacional de Serviços socioassistenciais, o PAIF não possui caráter terapêutico. As demandas em saúde mental devem ser encaminhadas para a rede intersetorial" (BRASIL, 2009).

Surge, portanto, o imperativo de se buscar novas estratégias e instrumentos de trabalho que sejam coerentes e contribuam com a realidade comunitária. Como alerta Dimenstein (2013), neste campo estamos diante da necessidade de

inventar meios de desestabilizar o regime de simplificação das formas de viver e a clínica dos limites, das essências, da natureza, das estruturas, das tendências. É preciso produzir um conhecimento heterogêneo, transdisciplinar, uma espécie de bricolagem que tem forma provisória, mas tem funcionalidade $e$ atende à multidimensionalidade da vida e à singularidade dos problemas enfrentados. (pp. 9-10).

Isto gerou tensões e fissuras na identidade do psicólogo que defronte de novas realidades precisou rever e ressignificar sua práxis para dar conta de uma realidade que não lhe parece ser tão familiar: a desigualdade social.

Para Sawaia (2009) a desigualdade social constantemente põe em risco a existência dos sujeitos que a ela encontram-se subjugados, uma vez que produz sofrimento na forma de tristeza cristalizada, bloqueando o poder do corpo e da alma de afetar e de ser afetado cerceando sua experiência, mobilidade e vontade. Confrontado com o sofrimento de sujeitos que lutam cotidianamente contra o risco de aniquilação de seus corpos, direitos, sonhos e existência, o profissional é interpelado quanto as contribuições do seu fazer, uma vez que sua atuação pode ir tanto no sentido de transformar a realidade injusta a partir do 
desenvolvimento de potencialidades do sujeito como também de garantir a manutenção do status quo.

Nesta conjuntura, em que o psicólogo lida com processos de alienação, nos quais ele mesmo pode estar imerso, em que as prioridades são definidas com base no enfrentamento dos riscos e perigos a que os sujeitos estão expostos, quando na situação de vulnerabilidade, esperar a demanda espontânea vir procurar os serviços não funciona efetivamente. É solicitado ao profissional ir ao encontro das demandas no lugar onde elas ocorrem. Por isso, é fundamental ver os territórios com outros olhos. Na PNAS, encontramos preconizada a atuação territorializada dos profissionais, que enfoque as relações de vizinhança, bem como as diversas relações que perpassam os territórios, quais sejam: social, econômica, histórica, política.

O território é onde os sujeitos constroem sua história, do qual se apropriam e que lhes oferece referenciais estáveis, os quais lhes servem à orientação e à preservação da identidade (Pol, 1996). Na PNAS, o território ganha centralidade nas ações preconizadas aos profissionais inseridos nos serviços, assim como o processo de territorialização é eleito como passo primeiro para a atuação dos técnicos do CRAS. Percebemos, portanto, que neste contexto o território deve ser mapeado, pesquisado e vivenciado pelos profissionais do equipamento.

Fazendo parte da equipe do CRAS, o psicólogo é convidado a intervir numa perspectiva interdisciplinar, orientando sua prática à prevenção de situações geradoras de vulnerabilidade social, em conjunto com ações que primam pelo fortalecimento de vínculos familiares e comunitários das pessoas que residem em seu território de abrangência. Dentre suas atribuições, como anteriormente citado, figura a prática do processo de territorialização.

Percebemos, portanto, que o território deve ser lido (Lynch, 2010), atento às relações intersubjetivas que potencializam a ação das pessoas no enfrentamento das expressões das questões sociais. A perspectiva da Psicologia Ambiental auxilia-nos nesta leitura ao considerar o estudo da interrelação pessoa-ambiente, chamando atenção para o fato de que o sujeito avalia, percebe e influencia o ambiente sociofísico e é igualmente influenciado por ele (Moser, 1998). Seguindo esta orientação teórica, os trabalhos realizados no Laboratório de Pesquisa em Psicologia Ambiental da Universidade Federal do Ceará - UFC apontam instrumentos que podem facilitar a inserção do psicólogo nos territórios que compõem o CRAS e dentre eles podemos citar o Instrumento Gerador dos Mapas Afetivos (IGMA) (Augusto \& Bomfim, 2014; Bomfim, 2010; Bomfim et al., 2014). Desta forma, o objetivo do presente trabalho é apresentar o IGMA como método capaz de auxiliar o psicólogo do CRAS, no processo de territorialização. 


\section{MÉTODO}

O Instrumento Gerador dos Mapas Afetivos (IGMA) foi construído por Bomfim (2010) em sua tese de doutorado, tendo como finalidade ser um método de investigação dos afetos em relação ao ambiente. Considerando a intangibilidade dos afetos, Bomfim (2010) define os Mapas Afetivos como um instrumento que facilita torná-los tangíveis, por meio de imagens, palavras e da "formulação de sínteses ligadas aos sentimentos, ligadas de forma menos elaborada e de forma mais sensível" (Bomfim, 2010 p. 137). A composição original do instrumento, direcionada a abordar os afetos dos sujeitos em relação à cidade, abrange o Desenho elaborado pelo respondente; o Significado do desenho atribuído também pelo participante; os Sentimentos; as Palavrassíntese; O que pensa da cidade; Categorias da Escala de tipo Likert; Comparação da cidade; Caminhos percorridos; Participação em associação; Participação eventual em movimentos sociais; e as Características sociodemográficas.

Em nossa prática de territorialização em um CRAS de Mossoró, no Rio Grande do Norte (RN), optamos por utilizar o IGMA, intentando desvelar os afetos dos usuários em relação ao território. Partimos da concepção espinosana de que a afetividade é parte inalienável do sujeito e de que o modo como ele é afetado pelos outros corpos pode potencializar sua ação, conduzindo-o à alegria e à liberdade, ou despotencializá-lo, gerando tristeza e passividade (Spinoza, 2005). Deste modo, tal investigação nos permite identificar no território fragilidades que entristecem os usuários e impedem os bons encontros, estes últimos caracterizados por Spinoza (2005) como aquilo que aumenta a potência de agir, assim como reconhecer as potencialidades que garantem ações voltadas ao bem comum e que fomentam a participação social dos sujeitos.

No processo de territorialização, dentre outras ações, é muito importante a formação de oficinas de territorialização realizadas nos mais diferentes lugares no território do CRAS e são nestas oficinas o momento que se mostrou ideal para sua aplicação. Ressaltamos que, apesar de o IGMA ser um instrumento originalmente destinado à pesquisa e posteriormente indicado para a intervenção, sua utilização em nosso caso não teve por finalidade a pesquisa acadêmica, mas sim a investigação dos afetos presentes em nosso território de atuação, a fim de que nossa prática profissional fosse mais contextualizada e coerente. Destarte, adaptamos o Instrumento para o nível bairro, já que a área de abrangência do CRAS é composta por alguns bairros com dinâmicas muito singulares e tencionávamos pensar estratégias posteriores que considerassem as peculiaridades de cada um.

O instrumento possui, portanto, uma parte qualitativa, na qual o respondente elabora imagens (desenhos e metáforas) e expressa seus sentimentos por meio da escrita, e uma parte quantitativa, que em nosso caso não foi utilizada, composta da escala de tipo Likert e que em sua análise recebe 
um tratamento estatístico complementar. A parte qualitativa é analisada a partir da análise de conteúdo categorial, conforme proposta por Vázquez-Sixto, e da análise do subtexto, do sentido e do motivo, tendo por base os estudos de Vigotski, o qual "toma os afetos como elementos constituintes do subtexto da linguagem sobre um objeto estudado." (Bertini, 2006, p. 135). Na Tabela 1 apresentamos a proposta de Bomfim (2010) para a construção do mapa afetivo, em que a autora define os elementos abordados no instrumento:

Tabela 1.

Síntese do processo de categorização para elaboração dos mapas afetivos

\begin{tabular}{ll}
\hline Categoria & Descrição \\
\hline Identificação & No \\
& Sexo: \\
& Idade: \\
& Escolaridade: \\
& Cidade: \\
& Tempo de residência (quando não originário). \\
& Mapa cognitivo de Lynch: desenho de monumentos, caminhos, \\
& limites, confluência e bairros. \\
& Metafórico: desenho que expressa, por analogia, o sentimento \\
& ou o estado de ânimo do respondente. \\
\hline Significado & Explicação do respondente sobre o desenho. \\
\hline Qualidade & Atributos do desenho e da cidade, apontados pelo respondente. \\
\hline Metáfora & Expressão afetiva do respondente ao desenho e à cidade. \\
& Comparação da cidade com algo pelo respondente, que tem \\
\hline Sentido & Interpretação dada pelo investigador à articulação de sentidos \\
& entre as metáforas da cidade e as outras dimensões atribuídas \\
& pelo respondente (qualidade e sentimentos).
\end{tabular}

Nota. Adaptado de Bomfim (2010, p. 151).

A análise do instrumento reporta-nos à relação do sujeito com o ambiente, que ocorre de modo cognitivo, afetivo e simbólico (Corraliza, 1998). Derivam desta formulação dos Mapas Afetivos (1) a estrutura do mesmo, se cognitiva, quando o sujeito centra-se em elementos existentes no ambiente físico, ou metafórico, quando o desenho e seu significado fazem relação à comparação do ambiente com uma outra coisa; e (2) as imagens, expressas no sentido do mapa, respaldadas pela base teórica da Psicologia Ambiental, quais sejam, segundo Bomfim (2010): o pertencimento, quando o sujeito sente que pertence ao lugar e que o lugar lhe pertence, para além da posse material, conforme o conceito de apropriação do espaço (Pol, 1996), neste caso o lugar é comparado com a própria casa, por exemplo; a agradabilidade, em que o respondente 
enfoca aspectos favoráveis do ambiente, capazes de suprir suas necessidades biológicas, psicológicas, econômicas e/ou sociais, assim o ambiente é caracterizado como agradável; a insegurança, que remete à sensação de instabilidade, de que algo inesperado pode acontecer, o que evoca sentimento de medo em relação ao ambiente; a destruição, em que ganham destaque os aspectos despotencializadores do ambiente, mais relacionados às características físicas, tais como sujeira, desgaste, mau organização espacial, entre outras; e os contrastes, que abrange polarizações potencializadoras e despotencializadoras ao mesmo tempo, remetendo à contradição ao qualificar o ambiente, ou seja, esta categoria descreve situações em que o sujeito considera o ambiente, por exemplo, bonito e feio, agradável e sufocante, alegre e angustiante, entre outras.

Estas imagens agregam-se para formar a Estima de Lugar, uma categoria ambiental socialmente construída, que aponta para a avaliação afetiva do sujeito em relação ao ambiente. A Estima de Lugar pode ser definida como:

uma forma específica de conhecimento, relativa ao aspecto de significado ambiental na dimensão de emoções e sentimentos sobre o ambiente construído. Como categoria social, a estima pode ser compreendida como uma forma de pensamento social que caminha em paralelo a outros de simbolismo do espaço, derivado da categoria de identidade social urbana ou de uma afetividade do lugar (Bomfim, 2010, p. 218).

A Estima de Lugar pode ser qualificada como potencializadora, quando se compõe das imagens de pertencimento e agradabilidade, ou despotencializadora, quando derivada da insegurança e da destruição (Bomfim, 2010). Cabe ressaltar que a imagem de contrastes é transversal às demais, podendo estar presente tanto na qualificação potencializadora como despotencializadora da Estima (Bomfim et al., 2014), isto significa dizer que mesmo o sujeito destacando aspectos desagradáveis do ambiente, os pontos potencializadores podem se sobrepor e fomentar o cuidado e o amor pelo lugar, assim como o oposto também pode ser verdadeiro e o sujeito sinta-se desvinculado do ambiente por considerá-lo despotencializador.

Destarte, Bomfim (2010) propõe a Estima de Lugar como um dos indicadores da participação e da implicação do sujeito com a cidade, em que a Estima potencializadora indica a vinculação com o ambiente e o aumento da potência de ação do indivíduo, enquanto a Estima despotencializadora gera predisposições negativas do indivíduo para com o ambiente (Bomfim, 2010).

Desta forma, a leitura psicossocial do território pelos afetos nos fornece um rico e denso material que será vital na elaboração de ações e intervenções no âmbito do CRAS que fortaleçam e estimulem situações potencializadoras de vida como também que enfraqueçam ou inibam situações despotencializadoras e de padecimento. 
No processo de territorialização que realizamos, aplicamos a parte qualitativa do IGMA com os moradores de um dos bairros da área atendida pelo CRAS, que será aqui denominado Bairro Raios de Sol, a fim de que os usuários não sejam identificados. Com a concordância dos usuários, a aplicação foi feita na residência dos moradores, em sua maioria com a chefe da família. Entregamos o instrumento impresso e o material necessário aos sujeitos e acompanhamos seu preenchimento, de maneira que pudéssemos esclarecer as dúvidas e dar o devido suporte, caso os participantes não fossem alfabetizados.

A versão adaptada para nossa realidade compôs-se da identificação do sujeito (sexo e idade), solicitação que o usuário desenhasse algo que para ele representa o bairro, atribuição de sentido ao desenho, os sentimentos e as palavras-síntese relacionadas ao desenho, e a metáfora, em que pedimos para o participante comparar o bairro com algo. Posteriormente, realizadas as análises, delineamos as potencialidades do bairro e buscamos pautar nossa prática em atuações capazes de fortalecer os vínculos existentes e fomentar a participação dos sujeitos nas ações, a partir da afetividade.

\section{O PROCESSO DE TERRITORIALIZAÇÃO DO CRAS À LUZ DA PSICOLOGIA AMBIENTAL}

O Ministério de Desenvolvimento e Combate à Fome (MDS) considera a Territorialização e a Matricialidade Sociofamiliar como os dois eixos estruturantes do CRAS. Isto significa dizer que o território e a família são colocados em relevo no trabalho social desenvolvido no âmbito da proteção básica. No nosso artigo nos detemos exclusivamente à Territorialização.

Para os profissionais da Psicologia, trabalhar com o território não é uma questão tão clara e evidente visto o ambiente tradicionalmente ter sido tratado como algo exterior, que está lá fora e que é de competência de outras disciplinas como a Geografia e Arquitetura.

Com isso, ao ingressar no CRAS como técnico de referência para operacionalizar a política de assistência social de acordo com sua formação e de modo interdisciplinar, o psicólogo se vê diante de um impasse. Como tratar o território? Pesquisas como a de Oliveira, Solon, Amorim e Dantas (2011) realizada com (20) psicólogos que atuam em (17) CRAS da região metropolitana de Natal-RN verificou que dentre as atividades / ações feitas no CRAS apenas em um (1) equipamento ocorria territorialização e nenhum psicólogo declarou realizar esta atividade/ação.

No que se refere à produção acadêmica sobre o tema, realizamos uma busca no Portal de Periódicos da Capes, com o cruzamento dos descritores "territorialização" e "CRAS" que retornou apenas três produções, sendo uma dissertação e dois artigos científicos (Macedo \& Dimenstein, 2012; Magalhães, Coelho, Nogueira \& Bocca, 2011; Martins, 2009), por seu turno o uso dos 
descritores "territorialização" e "Política Nacional de Assistência Social" encontramos apenas um ensaio (Pereira, 2010) diferente dos trabalhos supracitados. Por outro lado, a busca voltada para o campo da saúde mostra-se muito mais expressiva, retornando 164 artigos.

E quando a territorialização acontece no CRAS, muitas vezes, ela se limita a divisão do território para a atuação das equipes (Lougon, Cruz \& Santos, 2007) como também na identificação dos equipamentos sociais e número de beneficiários dos programas de transferência de renda.

Diante deste descompasso e sabendo-se que cada um destes campos apresenta suas especificidades e demandas particulares, chamamos atenção para a importância de tratarmos deste processo no âmbito do CRAS, tentando contribuir para sua realização.

Estes dados são sobremaneira preocupantes e apontam a emergência de pesquisas que investiguem a relação território e vulnerabilidades sociais para instrumentalizar o psicólogo nesta empreitada tão desafiadora e importante para a superação das desigualdades sociais.

No bairro onde aplicamos o IGMA, a categoria de maior destaque foi a agradabilidade, relacionada à avaliação de amor ao bairro, harmonia, alegria, união, entre outros. Não cabe aqui uma análise desses resultados, uma vez que nosso interesse é apresentar as potencialidades do instrumento para a prática do psicólogo e não o caso específico do bairro Raios de Sol, entretanto, com o consentimento de um dos participantes, apresentamos um dos mapas, a fim de que o leitor tenha maior compreensão de sua análise. Na Tabela 2 apresentamos o mapa afetivo de um dos moradores do bairro:

Tabela 2.

Mapa Afetivo do Sujeito 01

\begin{tabular}{ll}
\hline Categoria & Descrição \\
\hline Identificação & $\mathrm{N}^{\circ} 1$ \\
& Sexo: Feminino \\
& Idade: 54 anos \\
\hline Estrutura & Metafórico \\
\hline Significado & "Porque eu gosto daqui de Raios de Sol." \\
\hline Qualidade & Compreensão, amizade, união, calmo, tranquilo, sem medo. \\
\hline Sentimento & Alegria, felicidade, paz e amor. \\
\hline Metáfora & "Sítio porque é calmo como um sítio." \\
\hline Sentido & O bairro Sítio é em que a agradabilidade aparece na união, na \\
& tranquilidade, na segurança, alegria e amor pelo bairro. \\
\hline
\end{tabular}

Nota. Adaptado de Bomfim (2010) 
No instrumento, o sujeito desenhou um lugar bastante diferente daquele onde mora, remetendo muito mais a como percebe esse ambiente do que a real estrutura física dele, acrescentou árvores, uma casa com melhor estrutura e um terreno gramado na rua ao invés da pavimentação existente. Isto, junto ao significado atribuído ao desenho, permitiu-nos identificar a estrutura metafórica do mesmo. O bairro comparado a um sítio evoca a proximidade entre seus moradores e a satisfação com o entorno. Este dado, recorrente na maioria dos instrumentos aplicados, nos oferece pistas para guiar nossas atuações, indicando, por exemplo, a existência de implicação e cuidado para com o lugar, as relações de vizinhança, as redes de proteção e os possíveis parceiros de um bairro qualificado pela amizade e a felicidade.

Estas constatações apresentadas pelo instrumento nos permitem olhar o território em sua multidimensionalidade, no que ele tem de potencializador e/ou despotencializador, com vistas a propormos estratégias, junto à comunidade, capazes de expandir o que gera uma Estima Potencializadora e transformar o que se identifica como Estima Despotencializadora. Com isso, visa-se garantir espaços de bons encontros, uma maior participação social dos sujeitos e a busca pelo bem comum, de maneira que do próprio território venham as ações de prevenção e enfrentamento das vulnerabilidades.

Consideramos, portanto, as contribuições da Psicologia Ambiental incontestes nessa discussão na medida em que este campo do saber tem investigado a inter-relação pessoa-ambiente desde seus primórdios que remontam a meados de 1950. Dentro de uma perspectiva transacional (Mira, 1997), a Psicologia Ambiental objetiva o estudo das transações e interações entre as experiências humanas e o entorno sócio-físico (seja este último um espaço construído ou natural), o qual compõe a identidade do sujeito. Pode-se dizer que sua especificidade "é a de analisar como o indivíduo avalia e percebe o ambiente e, ao mesmo tempo, como ele está sendo influenciado por esse mesmo ambiente" (Moser, 1998, p. 122). Diante da complexidade desta proposta, a disciplina caracteriza-se pela pluralidade em sua epistemologia (Wisenfeld, 2005) e pela multiplicidade de métodos e técnicas de atuação, que abrangem contribuições de outras áreas.

O olhar da Psicologia Ambiental sobre os territórios relaciona a construção da subjetividade à identificação com os espaços (Moser, 1998). Com este posicionamento a Psicologia Ambiental tem desenvolvido produções que podem ser úteis para o psicólogo no seu trato com o território no processo de territorialização. Para prosseguir é premente tomar nota como a Política de Assistência Social define a territorialização. Portanto, de acordo com MDS:

A territorialização refere à centralidade do território como fator determinante para a compreensão das situações de vulnerabilidade e risco sociais, bem como para seu enfrentamento. A adoção da perspectiva da territorialização se materializa a partir da descentralização da política de assistência social e consequente oferta 
dos serviços socioassistenciais em locais próximos aos seus usuários.Isso aumenta sua eficácia e efetividade, criando condições favoráveis à ação de prevenção ou enfrentamento das situações de vulnerabilidade e risco social, bem como de identificação e estímulo das potencialidades presentes no território (Brasil, 2009, p.13).

E ao que concerne ao território à compreensão é que ele:

não se restringe à delimitação espacial. Constitui um espaço humano, habitado. Ou seja, o território não é somente uma porção específica de terra, mas uma localidade marcada pelas pessoas que ali vivem. É nos espaços coletivos que se expressam a solidariedade, a extensão das relações familiares para além da consanguinidade, 0 fortalecimento da cumplicidade de vizinhança e o desenvolvimento do sentimento de pertença e identidade. O conceito de território, então, abrange as relações de reconhecimento, afetividade e identidade entre os indivíduos que compartilham a vida em determinada localidade. (Brasil, 2011, p.13).

Neste sentido, a atuação do psicólogo não pode prescindir da territorialização, ele é um processo contínuo e é por meio dele que o psicólogo conhecerá as potencialidades e vulnerabilidades da comunidade para a construção de intervenções que façam sentido para a comunidade.

É justamente nestes espaços de vida que aliam o espaço físico e a identidade (Santos, 1999), onde os diversos poderes atuam, interesses e forças sociais embatem-se, nos quais os sujeitos (re)criam sua realidade, sofrendo os danos da exploração, mas também produzindo formas criativas de enfrentá-la, que o processo de territorialização pode contribuir, mapeando riscos e potencialidades, bem como pondo luz à relação dialética sujeito-ambiente. Neste processo, o território é visto não somente como o palco onde a vida acontece, mas como uma construção simbólica, cultural e afetiva que forjam subjetividades.

O psicólogo, portanto, como disse Guareschi, sai de sua posição daquele que espera, para aquele que vai ao encontro de, se tornando não mais o contemplador de rio, mas o próprio rio. Tornar-se parte reconhecida na comunidade é vital para o sucesso das pretensas intervenções e fazer parte da comunidade é conhecer o outro pelo nome e ser conhecido também (Guareschi, 2008).

Diante destas afirmativas, podemos questionar: $O$ psicólogo tem sido preparado para trabalhar com o território? Como é que a prática do psicólogo pode estar relacionada com o território? A formação em Psicologia oferece subsídios para compreender o território numa concepção psicossocial? Quais instrumentos estamos produzindo para viabilizar nossas práticas?

O mapa afetivo pretende ser um instrumento de avaliação e de intervenção nos ambientes micro e macrossociais, que envolve as dimensões tanto da construção de significados como do que é considerado físico. Com base no que foi discutido acerca do processo de territorialização, propomos os Mapas 
Afetivos como método que, a nosso ver, pode contribuir com esta prática do psicólogo nos territórios atendidos pelos CRAS.

\section{CONSIDERAÇÕES FINAIS}

Como vimos, o processo de territorialização é algo contínuo, nunca está pronto e acabado, mas é vivo e que sempre demanda atenção do psicólogo. A possibilidade de entrar em contato com a dimensão afetiva por meio dos Mapas Afetivos possibilita a construção de intervenções que fortaleçam os vínculos comunitários e familiares das pessoas que fazem parte da área de abrangência do CRAS.

O território é constituído pelas relações interpessoais e, além de ser impregnado de simbolismo, participa da constituição subjetiva das pessoas numa relação bidirecional. Sendo assim, o CRAS tem um papel fundamental na produção e promoção de significados e sentidos porque concebe o território não apenas como o palco de desigualdades sociais, mas um ambiente potencializador de vida cujas atividades e intervenções valorizam a interrelação pessoa e ambiente com o intento de uma mútua transformação que expresse qualidade de vida para todos.

Seguindo esta lógica, o psicólogo deve utilizar instrumentos construídos na história da Psicologia que valorizem o território como potencializador de ação. Nesse cenário, o IGMA aparece como um recurso importante para a identificação dos modos como as pessoas estão implicadas com os lugares que habitam, assim como o quanto implicam-se com seu desenvolvimento e a proteção dos outros e dos ambientes. Acreditamos que pela via da afetividade torna-se possível desestabilizar o sistema vigente, como propôs Dimenstein (2013) para a atuação do psicólogo no campo da assistência social, por meio de um compromisso ético-político fomentado na coletividade. Romper o status quo, a lógica de dominação e opressão, que gera fragilidades e vulnerabilidades no território, implica instrumentalizar as pessoas da comunidade para transformarem as vulnerabilidades sociais em potências de vida e de ação.

\section{REFERÊNCIAS}

Augusto, D. M. \& Bomfim, Z. A. C. (2014, setembro). A utilização dos Mapas Afetivos como instrumento metodológico na atuação do psicólogo no Centro de Referência de Assistência Social. In V. M. Ximenes, (Org.), Psicologia social no mundo atual: desafios, limites e fazeres. Trabalho apresentado na V Conferência Internacional de Psicologia Comunitária, Fortaleza, CE (p.967). Fortaleza: Universidade Federal do Ceará.

Bertini, F. M. A. (2006). Centro de Fortaleza, lugar de transformações: o idoso e os afetos implicados (Dissertação de Mestrado). Recuperado de 
http://www.pospsi.ufc.br/index.php/dissertacoes/54-dissertacoes-3 Bomfim, Z. A. C., Nobre, B. H. L., Ferreira, T. L. M., Araújo, L. M. A., Feitosa, M. Z. S., Martins, A. K. S.,..., \& Farias, N. F. (2014). Affective maps: validating a dialogue between qualitative and quantitative methods. In R. G. Mira \& A. Dumitru (Eds), Urban Sustainability: Innovative spaces, vulnerabilities and opportunities (131-147). Coruña: Institute of Psychosocial Studies and Research "Xoan Vicente Viqueira".

Bomfim, Z. A. C. (2010). Cidade e Afetividade: Estima e construção dos mapas afetivos de Barcelona e de São Paulo. Fortaleza, CE: Edições UFC.

Brasil. (2012). Orientações Técnicas sobre o PAIF: trabalho social com famílias do Serviço de Proteção e Atenção à Família- PAIF (Vol. 1). Brasília, DF: Ministério do Desenvolvimento Social e Combate à Fome.

Brasil. (2010). O CRAS que temos, o CRAS que queremos. Orientações técnicas, Metas de desenvolvimento dos CRAS (Vol. 1). Brasília, DF: Ministério do Desenvolvimento Social e Combate à Fome.

Brasil. (2009). Orientações Técnicas: Centro de Referência de Assistência Social - CRAS. Brasília: DF: Ministério do Desenvolvimento Social e Combate à Fome.

Carlson, A. C. R. \& Pinheiro, L. S. (2013). Práticas intersetoriais: Novos desafios postos aos psicólogos na atual política de assistência social. In L. R. Cruz, L. rodrigues, \& N. M. F. Guareschi (Eds.), Interlocuções entre a Psicologia e a Política Nacional de Assistência Social (pp. 103-117). Santa Cruz do Sul: EDUNISC.

Corraliza, J. A. (1998). Emoción y ambiente. In J. I. Aragonés \& M. Amérigo (Eds.) Psicologia ambiental (pp. 59-76). Madrid, Espanha: Ediciones Pirâmide.

Dimenstein, M. D. (2013). Práticas psicológicas e políticas públicas: A vida que emerge na diversidade. In L. R. Cruz, L. rodrigues, \& N. M. F. Guareschi (Eds.), Interlocuções entre a Psicologia e a Política Nacional de Assistência Social (pp. 8-10). Santa Cruz do Sul: EDUNISC.

Guareschi, P. (2008). Qual a prática da psicologia social da ABRAPSO? In A. V. Zanella, M. J. T. Silqueira, L. A. Lhullier, \& I. S. Molon (Eds.), Psicologia e Práticas Sociais (pp. 3-8). Rio de Janeiro, RJ: Centro Edelstein de Pesquisas Sociais.

Lougon, A. N., Cruz. M. F. S. \& Santos, P. A. (2007, agosto). O Território e a Política de Assistência Social. In Anais da III Jornada Internacional de Políticas Públicas: questão social e desenvolvimento no século XXI (pp. 0107). São Luís: Universidade Federal do Maranhão.

Martins, M. L. P. (2009). O Processo de Implantação de CRAS na Região da AMEPAR: Refletindo sobre os caminhos da mudança. (Dissertação de Mestrado) Recuperado de http://www.bibliotecadigital.uel.br/document/?view=vtls000151912 
Mira, R. G. (1997). La Aportación de la Psicología Ambiental. In R. G. Mira, La ciudad percibida: Una Psicología Ambiental de los Barrios de A Coruña (pp. 23-36). Coruña, Espanha: Servicio de Publicacións.

Moser, G. (1998). Psicologia Ambiental. Estudos de Psicologia, 3(1), 121-130. doi: $10.1590 /$ S1413-294X1998000100008

Oliveira, I. F., Solon, A. F. A. C., Amorim, K. M. O., \& Dantas, C. M. B. (2011). A prática psicológica na proteção social básica do SUAS. Psicologia \& Sociedade, 23(n. esp), 140-149. doi: 10.1590/S0102-71822011000400017

Pereira, T. D. (2010). Política Nacional de Assistência Social e território: enigmas do caminho. Katálysis, 13(2), 191-200. doi: 10.1590/S141449802010000200006

Pol, E. (1996). La apropiación del espacio. In L. Iñigues \& E. Pol, Cognición, representación y apropiación del espacio (pp. 45-62). Barcelona, Espanha: Monografies Sócio/ambientais.

Santos, M. (1999). O dinheiro e o território. GEOgraphia, 1(1), 7-13. Recuperado de http://www.uff.br/geographia/ojs/index.php/geographia/article/view/2/2

Sawaia, B. B. (2009). Psicologia e desigualdade social: Uma reflexão sobre liberdade e transformação social. Psicologia \& Sociedade, 21(3), 364-372. Recuperado de: http://www.scielo.br/pdf/psoc/v21n3/a10v21n3.pdf

Spinoza, B. (2005). Ética: demonstrada à maneira dos geômetras. São Paulo, SP: Martin Claret.

Wiesenfeld, E. A. (2005) Psicologia Ambiental e as diversas realidades humanas. Psicologia USP, 16(1-2), 53-69. doi: 10.1590/S0103-65642005000100008

Sobre os autores

Diego Menezes Augusto é psicólogo e mestrando em Psicologia pela Universidade Federal do Ceará- UFC. E-mail: diego_psicologia@hotmail.com

Maria Zelfa de Souza Feitosa é psicóloga, mestre em Psicologia e doutoranda em Psicologia pela Universidade Federal do Ceará-UFC. E-mail:

maria.zelfa@hotmail.com

Zulmira Áurea Cruz Bomfim é Doutora em Psicologia e professora do Departamento de Psicologia da Universidade Federal do Ceará-UFC. É coordenadora do Laboratório de Pesquisa em Psicologia Ambiental da UFC. Email: zulaurea@gmail.com

Recebido em: 11/11/2015 $1^{a}$ revisão em: 29/02/2016 $2^{a}$ revisão em: 11/03/2016

Aceito em: $14 / 03 / 2016$ 